\title{
POPULATION DENSITY, DIURNAL ACTIVITY AND EFFECT OF TRAP HEIGHT ON CAPTURING OF PEACH FRUIT FLY, Bactrocera zonata (SAUNDERS) AND MEDITERRANEAN FRUIT FLY, Ceratitis capitata (WIEDEMANN) IN GUAVA ORCHARDS AT NUBARIA REGION, EGYPT DARWISH, A. A. E.
}

Plant Protection Department, Faculty of Agriculture, Damanhour University, Egypt

\begin{abstract}
Field experiments (from December 2012 to December 2013) were carried out to study the population density, the optimum trap height and optimum time for trapping the peach fruit fly (PFF), Bactrocera zonata and Mediterranean fruit fly (MFF), Ceratitis capitata in Guava orchards at Nubaria district, Beheira Governorate, Egypt, using Jackson traps provided with the sex attractants Methyl eugenol (for PFF) and trimedlure (for MFF). Generally, Males of $B$. zonata were caught in higher number than $C$. capitata and the difference between the two flies was statistically high significant. The traps were hung at the height of 1,2, 3 and 4 meter from ground level and the captured males were weekly recoded. It was noted that significantly highest number of males of $B$. zonata were captured in the trap hung at $3 \mathrm{~m}$ height and the highest number of males of $C$. capitata was recorded at $4 \mathrm{~m}$ height. Also, the results revealed that the significantly highest number of male flies of $B$. zonata $(1.02 \pm 0.11$ males /trap /hour) and $C$. capitata $(0.59 \pm 0.07$ males /trap /hour) were recorded during the period from $7.00-10.00 \mathrm{am}$.
\end{abstract}

\section{INTRODUCTION}

The tephritid flies are among the major pests of fleshy fruits which affect production throughout the world and represent the most economically important group of polyphagous Diptera (Robinson and Hooper, 1989). The Mediterranean fruit fly or Medfly, Ceratitis capitata (Wiedemann), is one of the world's most destructive fruit pests. The species originates in the Mediterranean region of South Europe and North Africa. This pest attacks more than 260 different fruits and nuts. Thin-skinned, ripe, succulent fruits are preferred. Host preferences vary in different regions. An extensive host list is provided by Weems (1981). The peach fly, Bactrocera zonata (Saunders) originates in South and South-East Asia, where it attacks many fruit species (more than 50 host plants), including guavas, mangoes, peach, apricots, figs and citrus (White and Elson-Harris, 1992). In Egypt and other countries in the world, the peach fruit fly, B. zonata Saunders and the Mediterranean fruit fly, C. capitata are a major threat to fruits. These pests attack fruits of many species including guava; peach; mango and citrus, (Khan, 1994 and Fletcher, 1987). The effectiveness and use of traps in capturing and monitoring the population of $C$. capitata in fruit groves and orchards were described and discussed by many researchers such as Harries, et al. (1971), El-Sayed et al.(1992) and Mogahed (1999). Also, the effect of height of traps on captured fruit flies were studied and discussed by Siddique et al. (2003) in Pakistan 
and El-gendy (2012) in Egypt. The present study aimed to determine the population DENSITY of fruit flies, the appropriate trap height and to study the diurnal activity of males of both $B$. zonata and $C$. capitata in guava orchard at Nubaria district, Egypt. Previous understanding the behavior and the seasonal fluctuation of the fruit fly population may contribute to improve the integrated management for the pest.

\section{MATERIAL AND METHODS}

The present experiments were carried out from the $7^{\text {th }}$ of December 2012 to the $6^{\text {th }}$ of December 2013 in a guava (Psidium guajava L.) orchard of sandy soil (about five feddans) that located in Nubaria district, Beheira Governorate, Egypt. The trees (about 14 years old) which cultivated at $7 \times 7 \mathrm{~m}$ distances were irrigated by drip irrigation system.

The $1^{\text {st }}$ experiment was planned to determine the population density of the two fruit flies, $C$. capitata and Bactrocera zonata and differences between the two fly populations. Twelve Jackson traps for each fly were baited with the sex attractants in capsule lure; methyl eugenol (for PFF) and trimedlure (for MFF) supplemented by Plant Protection Institute. The capsules were fixed on the bottom of the traps. Each sticky board of the trap was weekly replaced by new one. The capsules were regularly exchanged every month. These traps were randomly distributed about $50 \mathrm{M}$ apart on guava trees.

The $2^{\text {nd }}$ experiment was planned to determine appropriate trap height for the two species of fruit flies, where traps were hung at heights of $1,2,3$ and $4 \mathrm{~m}$ from ground level. The experiment was replicated three times (3 traps for each height). The treatments were arranged in a randomized complete block design (RCBD).

In the $3^{\text {rd }}$ experiment, the observations were initiated to note the diurnal activity of males of both MFF and PFF. For this purpose twelve traps were inspected Five times in Friday from each week all over the year of study at $7.00,10.00,13.00,16.00$ and 19.00 to determine the number of males/trap /hour during the period from 7.00 to 19.00 . The results obtained were subjected to statistical analysis to obtain definite conclusions. Analysis of variance and means were separated by least significant differences test (LSD).

\section{RESULTS AND DISCUSSION}

\section{Population DENSITY of Peach Fruit Fly, Bactrocera zonata and Mediterranean Fruit Fly, Ceratitis capitata in Guava Orchard:}

The average values of weekly numbers of the population fluctuation of $B$. zonata and $C$. capitata males were used to calculate the average of monthly CTD (Capture of flies /Trap /Day). The obtained data are summarized in Table (1) and Fig. (1). It was found that the captured males of both species varied from one month to another throughout the year. The maximum abundance of $B$. zonata was recorded during October (20.52\%), 
but the minimum abundance was recorded during January (1.04\%). The fly was active through the whole year. Concerning the medfly $C$. capitata, the highest seasonal incidence of flies of $23.68 \%$ was shown in November, while the minimum seasonal incidence of the pest $(0.57 \%)$ was recorded in February. Mohamed (2002), at Sohag Governorate in Egypt mentioned that the caught flies of $B$. zonata were concentrated at August, September and October, while in the rest of the year the flies disappeared or were in shown few numbers during the three successive years of investigation of 1999-2001. But, the present results disagreed with those obtained by Mohamed (2003) who recorded the highest peak of $B$. zonata was on September $26^{\text {th }}$ on guava fruits.

The results also indicated that the attracted males of both $B$. zonata and $C$. capitata occurred in high numbers in August, September, October and November (ripening and maturity stages of Guava fruits). Statistical analysis showed that the differences between the CTD numbers of $B$. zonata and $C$. capitata were high significant $(P=0.01)$, where the population of $B$. zonata was higher than the population of $C$. capitata. These results are in agreement with Mohammed (2003) and Hashem et al. (2001), who demonstrated the population fluctuation of medfly, $C$. capitata and peach fruit fly $B$. zonata by weekly mean captures of males per trap showed that $B$. zonata surpassed the infestation in all the examined orchard. On other hand, Darwish (2012) showed that $C$. capitata surpassed $B$. zonata in citrus orchards.

Table (1): Mean of monthly captured B. zonata and C. capitata males/trap/day (CTD) by Jackson trap baited with methyl eugenol and trimedlure in guava orchards at Nubaria district:

\begin{tabular}{|c|c|c|c|c|}
\hline \multirow{2}{*}{ Months } & \multicolumn{2}{|c|}{ PFF } & \multicolumn{2}{c|}{ MFF } \\
\cline { 2 - 5 } & CTD \pm SE & $\begin{array}{c}\% \text { of } \\
\text { Incidence }\end{array}$ & CTD $\pm S E$ & $\begin{array}{c}\% \text { of } \\
\text { Incidence }\end{array}$ \\
\hline December & $0.83 \pm 0.416$ & 1.66 & $1.20 \pm 0.27$ & 3.80 \\
\hline January & $0.52 \pm 0.041$ & 1.04 & $0.29 \pm 0.04$ & 0.92 \\
\hline February & $0.61 \pm 0.105$ & 1.22 & $0.18 \pm 0.035$ & 0.57 \\
\hline March & $1.33 \pm 0.121$ & 2.66 & $1.12 \pm 0.37$ & 3.55 \\
\hline April & $2.80 \pm 0.285$ & 5.59 & $1.88 \pm 0.17$ & 5.95 \\
\hline May & $3.09 \pm 0.221$ & 6.17 & $2.05 \pm 0.26$ & 6.49 \\
\hline June & $4.06 \pm 0.189$ & 8.11 & $2.52 \pm 0.15$ & 7.98 \\
\hline July & $3.51 \pm 0.137$ & 7.01 & $2.02 \pm 0.217$ & 6.39 \\
\hline August & $5.13 \pm 0.159$ & 10.25 & $1.86 \pm 0.22$ & 5.89 \\
\hline September & $8.51 \pm 0.787$ & 17.00 & $4.31 \pm 0.21$ & 13.64 \\
\hline October & $10.27 \pm 0.372$ & 20.52 & $6.68 \pm 0.53$ & 21.15 \\
\hline November & $9.39 \pm 1.11$ & 18.76 & $7.48 \pm 0.65$ & 23.68 \\
\hline Mean $\pm S E$ & \multicolumn{2}{|c|}{$4.23 \pm 0.48$} & \multicolumn{3}{|c|}{$2.69 \pm 0.33$} \\
\hline
\end{tabular}




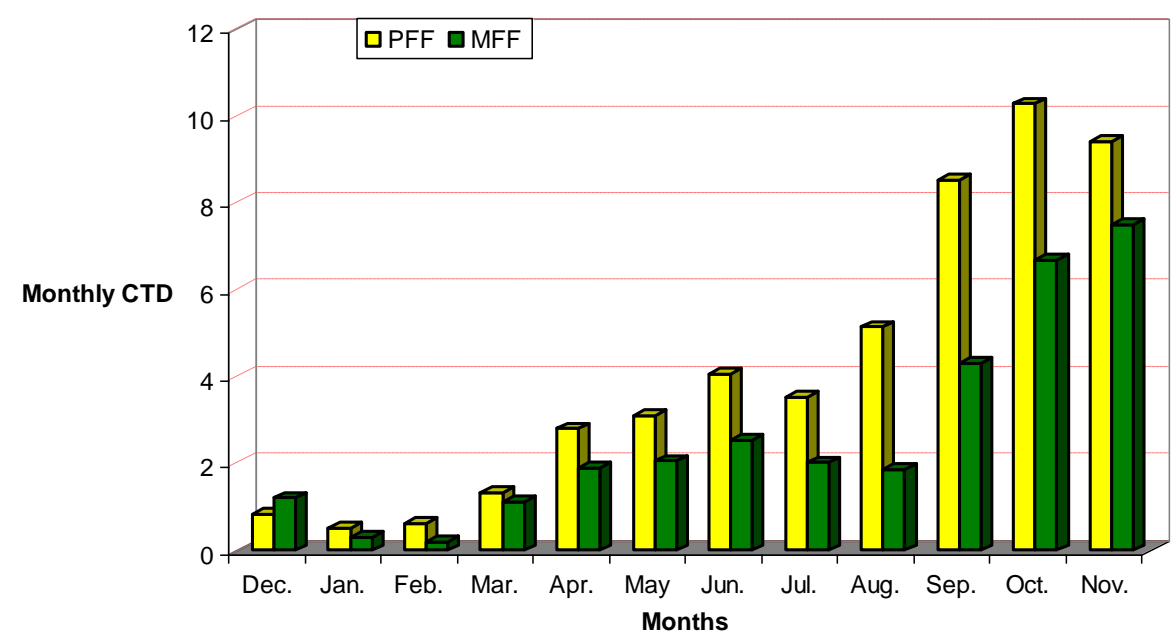

Fig. (1): Monthly fluctuation of $B$. zonata and $C$. capitata on guava trees at Nubaria district, Beheira Governorate, during 2013 year.

\section{Effect of Trap Height on the Captured Males of Fruit Flies:}

Effect of height of trap on the catches of adults of $B$. zonata and $C$. capitata (male/trap/day) was studied in guava orchard during 2013 year. Analysis of variance revealed that the variations in the number of trapped flies were significantly varied according to the different heights.

Captures of $B$. zonata males were significantly affected by trap height $(F=5.93 ; d f=3,208 ; P<0.05)$, where more $B$. zonata males caught at $3 \mathrm{~m}$ within canopies of guava trees than that of traps placed at $2 \mathrm{~m}$ (standard trap height) and 4 or $1 \mathrm{~m}$ (Table 2). Overall, about two times the numbers of flies were captured by traps placed at $3 \mathrm{~m}$ compared to traps hung at lower positions. These results are in disagreement with El-Gendy (2012) who stated that $1.5 \mathrm{~m}$ was the best position for hanging traps for more attraction of PFF males in an orchard of 5 feddans contains various host trees; mandarins, navel orange, figs, mangoes and grapefruits at Beheira Governorate. While Siddiqui et al. (2003) in Pakistan, stated that significantly highest number of flies of $B$. zonata were captured in the traps hung at 10 feet than 2, 4, 6 and 8 feet.

Concerning $C$. capitata, flies captures were significantly affected by trap location $(F=4.09 ; d f=3,208 ; P<0.05)$. Significantly more flies were caught in traps hung at $4 \mathrm{~m}$ compared to traps placed at 1,2 or $3 \mathrm{~m}$ heights (Fig. 2). The obtained results revealed that fruit flies ( $B$. zonata and $C$. capitata) activity was the greatest in the uppermost portion of guava trees canopy; thus, traps placed higher in the tree may be more attractive to flies that are active in the upper canopy compared to those placed lower in the tree canopy. Finally, the sensitivity and accuracy of monitoring for fruit flies may be improved through trap placement in a location where flies are most abundant. Holbrook and Fujimoto (1969) determined the heights at which lure 
traps could attract the fruit flies. They stated that the traps placed at 6 and 15 feet above the ground level captured significantly more number of Mediterranean fruit flies than trap placed at $0.1-2$ feet. Hooper and Drew (1979) in a rain forest environment found that the captures of tephritid fruit flies responding to cuelure and methyl eugenol increased as the height of the trap above ground was increased from 0.1 to $12.2 \mathrm{~m}$. In an open forest environment dominated by eucalypts no effect of trap height was found. No effect of height on captures of flies with cuelure or methyl eugenol in a citrus orchard or in suburban gardens was found within the range 0.1-3.6 $\mathrm{m}$ above ground. Opp et al. (2000) during field studies in orchards hung two traps per trees. One of the traps was hung high ( $5 \mathrm{~m}$ from the ground), while the second trap was hung low in the canopy ( $2 \mathrm{~m}$ from the ground). High traps captured greater number of both sexes of flies than low traps.

\section{Effect of time of day (Diurnal Activity):}

The effect of time of day or diurnal activity of fruit flies was studied for the two fruit flies, $B$. zonata and $C$. capitata. The variations in the numbers of trapped males of $B$. zonata and $C$. capitata were significantly differed during the periods of study (Table 3 ). Concerning $B$. zonata the maximum population (1.02 $\pm 0.11 \mathrm{male} /$ trap / hour) was recorded during the period from 7.00-10.00 $h$ at morning followed by the period from 10.00 to $13.00(0.18 \pm 0.029)$ then the period from 13.00 to $16.00(0.16 \pm 0.019)$ and the lowest number $(0.11 \pm 0.015)$ was recorded during the period from 16.00 to $19.00 \mathrm{~h}$. Similar results were obtained in case of $C$. capitata.

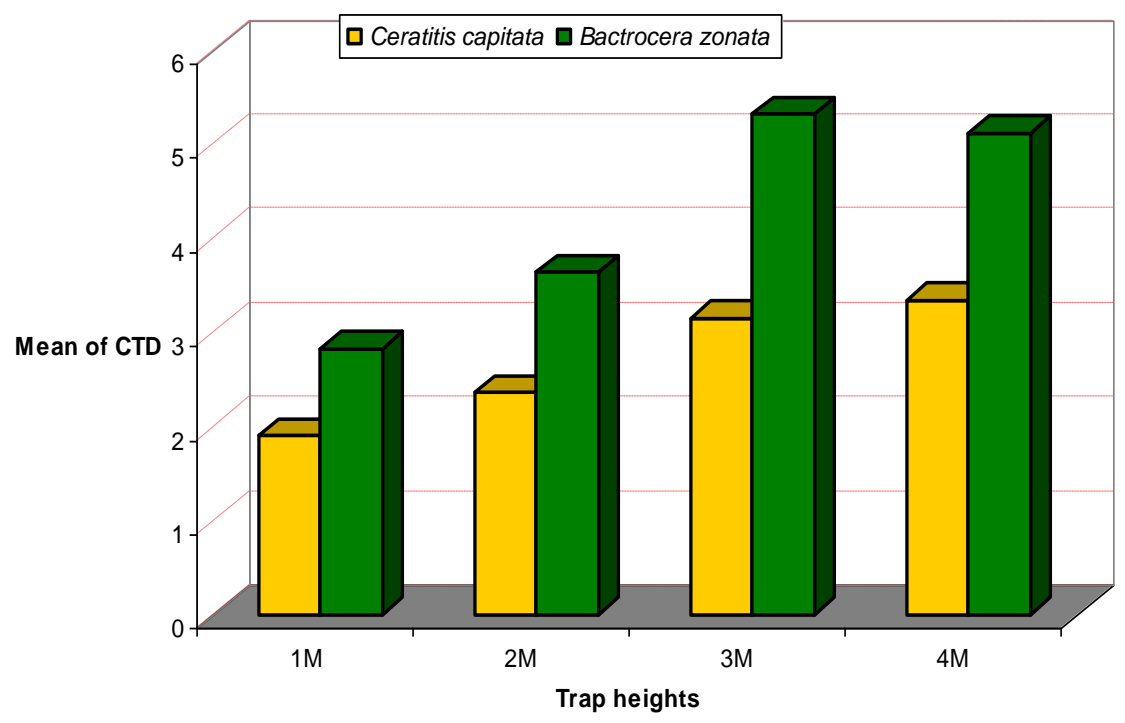

Fig. (2): Effect of height of traps on the captured males of fruit flies ( $B$. zonata and C. capitata) at Nubaria district, Beheira Governorate, Egypt. 
DARWISH, A. A. E.

2 
J. Plant Prot. and Path., Mansoura Univ., Vol.5 (1), January, 2014

3 
There were significantly different between the tested periods, where the maximum population was recorded during the period from 7.00 to 10.00 $(0.59 \pm 0.07$ male /trap /hour), followed by the period from 13.00 to 16.00 $(0.13 \pm 0.015$ flies /trap /hour) then $0.12 \pm 0.014$ male /trap /hour during the period from 10.00 to 13.00 . The lowest number of male /trap /hour $(0.07 \pm 0.01)$ was recorded during the period from $16.00-19.00$. Therefore, it is suggested that the control methods (partial bait spray) might be adapted during the morning hours to attract and kill sufficient number of flies. Kazi (1976) noted that fruit flies were most active at 10-11 h, adult flies spent much of the day resting on other plants in the vicinity of cucurbit crops, largest population of adult was found in these plants before $8 \mathrm{~h}$ and after 17 h. Stegeman et al. (1979) noted that the adult fruit flies were attracted to specific chemical lure earlier during the day time and peak attraction and population occurred earlier in the day during summer than spring season.

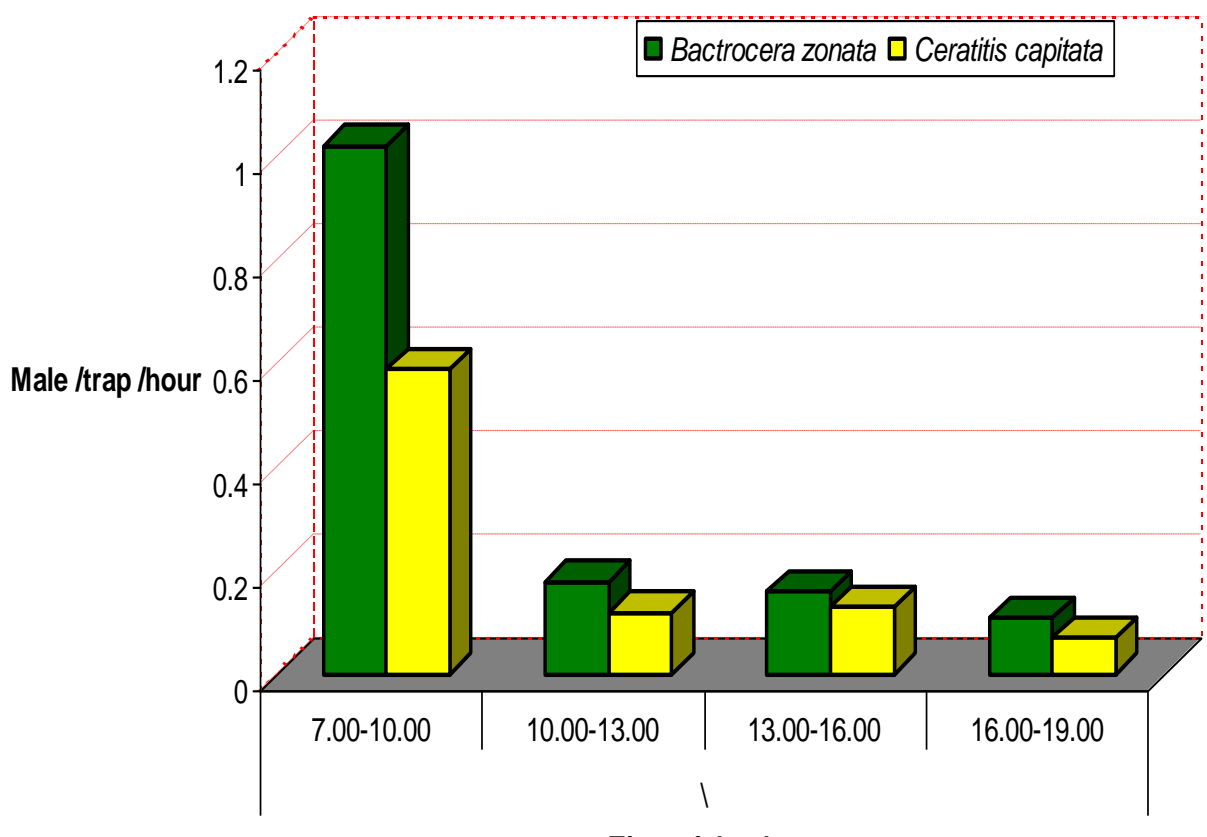

Time of the day

Fig. (3): Effect of the time of the day on the capture males of fruit flies (B. zonata and C. capitata) at Nubaria district, Beheira Governorate, Egypt. 


\section{REFERENCES}

Darwish, A. A. E. (2012): Monitoring the changes in population density of insect pests inhabiting fruit orchard fields. Ph. D. Thesis, Fac. of Agric. Damanhour Univ, 143pp

El-Gendy, I. R. (2012): Elevation of attraction efficiency of Jackson trap on peach fruit fly, Bactrocera zonata (Saunders). International Journal of Agriculture Research. ISSN 1816-4897 / DOI: 10.3923/ijar.

El-Sayed, A. M. K., Y. A. Darwish and S. H. Mannaa (1992): Evaluation of certain trapping systems for capturing the Mediterranean fruit fly, Ceratitis capitata (Wiedemann) in Assiut, Egypt, Assiut J. Agric. Res., 23: 249-274.

Fletcher, B. S. (1987): The biology of Dacine fruit flies. Ann. Rev. Entomol., 32: 115-144.

Harris, E. J.; S. Nakagaw, A. and T. Urago, (1971): Sticky traps for detection and survey of three tephritids. J. Econ. Entomol., 64: 62-65.

Hashem, A. G.; S. M. A. Mohamed and M. F. El-Wakkad (2001): Diversity and abundance of Mediterranean and peach fruit fly (Diptera: Tephritidae) in different horticultural orchards. Egyptian Journal of Applied Sciences, 16(2): 303-314.

Holbrook, F. R. and S. M. Fujimoto (1969): Mediterranean fruit flies and melon flies trapped at various heights with synthetic lure. J. Econ. Entomol., 62: 962-963.

Hooper, G. H. S. and R. A. I. Drew (1979): Effect of height of trap on capture of tephritid fruit flies with cuelure and methyl eugenol in different environments. Environmental Entomology, 8 (5): 786-788.

Kazi, A. S., (1976): Studies on the field habits of adult's melon fruit fly, Dacus (Strumeta) cucurbitae Coquikllett. Pak. J. Sci. Ind. Res., 19: 71-76

Khan, I. (1994): Introduction to Horticulture. National Book Foundation, Islamabad, Pp. 633.

Mogahed, M.I. (1999): Suitability of pheromone traps for monitoring and suppressing the population of Ceratitis capitata (Wied) on Mandarin trees. J. Egypt. Ger. Soc. Zool, 30 (E): 49-60.

Mohamed A. A. A. (2003): Studies on the peach fruit fly, and its control in Fayoum Governorate. M. Sc. Thesis, Fac. of Agric. El-Fayoum. Cairo Univ.

Mohamed, A. M. (2002): Seasonal abundance of peach fruit fly, Bacterocera zonata (Saunders) with relation to prevailing weather factors in Upper Egypt. Assuit J. Agric Sci., 33(2):195-207.

Opp, S. B., K. M. Reynolds, C. Pickel and W. Olson, (2000): Monitoring guidelines improved control of walnut husk fly in California. In: Areawide control of fruit flies and other insect pest. K. H. Tan. (Ed.) Penerbit Universiti Sains Malaysia

Robinson, A. and G. Hooper (1989): fruit flies, their biology, natural enemies and control. World Crop Pests. Elsevier, Amsterdam. 
Siddiqui, Q. H.; N. Ahmed, S. M. M. Shah Rashdi and S. Niazi (2003): Effect of time of the day and trap height on the catches of peach/guava fruit flies, Bactrocera zonata (Saunders) through Male annihilation technique. Asian Journal of Plant Sciences, 2(2): 228-232

Stegeman, B. R.; M. J. Riee and G. H. Hooper (1979): Daily periodicity in attraction of male tephritid fruit flies to synthetic chemical lures. RAE, Series-A., 67:11.

Weems, H. V. Jr. (1981): Mediterranean fruit fly, Ceratitis capitata (Wiedemann) (Diptera: Tephritidae). Entomology Circular No. 230. Fla. Dept. Agric. And Consumer Serv., Division of Plant Industry.

White, I.M. and M.M. Elson-Harris. (1992): Fruit flies of economic significance, their identification and bionomics. Wallingford, UK; CAB International, $\mathrm{Pp} 601$.

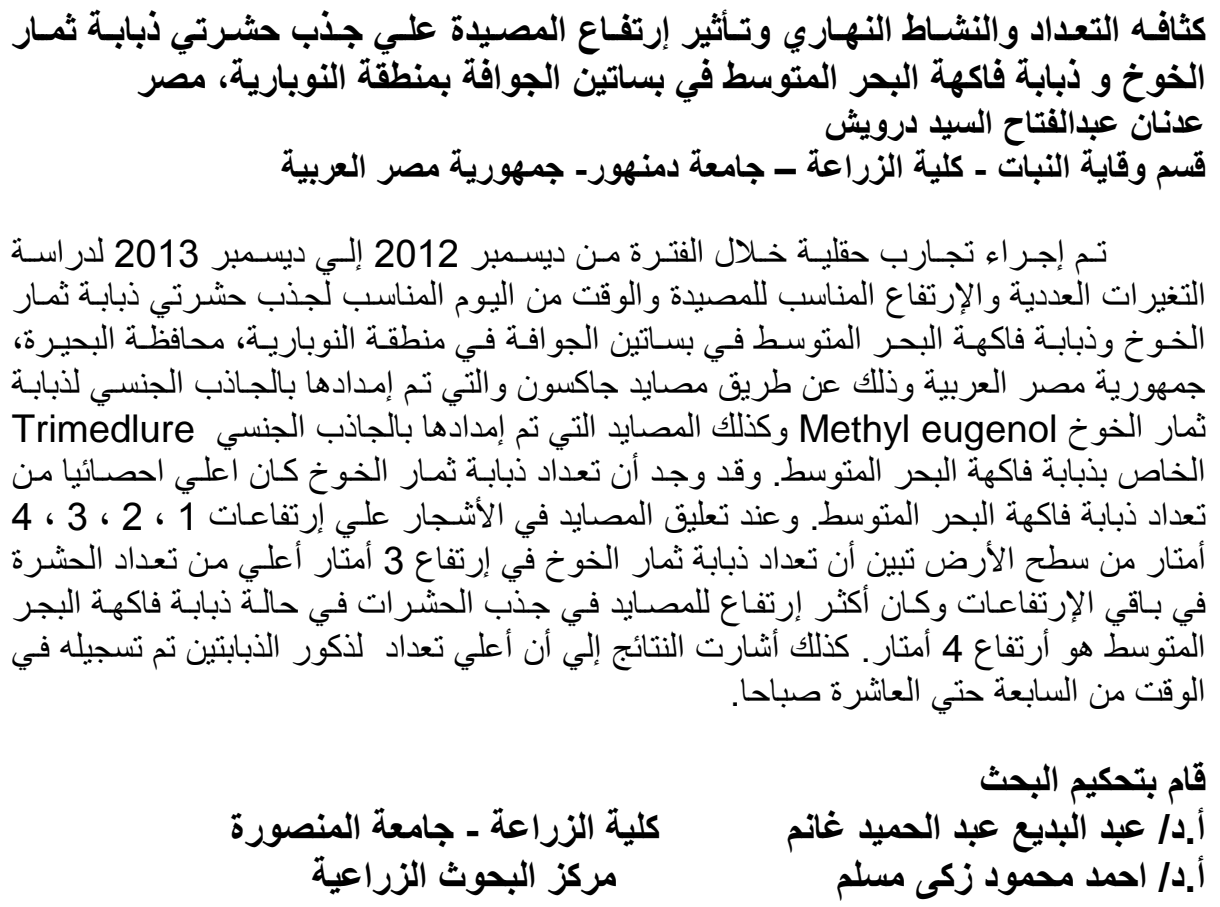


Table (2): Effect of height of traps on the captured males of fruit flies (B. zonata and C. capitata) at Nubaria district, Beheira Governorate, Egypt during 2013 year:

\begin{tabular}{|c|c|c|c|c|c|c|c|c|}
\hline \multirow{3}{*}{ Months } & \multicolumn{8}{|c|}{ Trap heights } \\
\hline & \multicolumn{4}{|c|}{ PFF ( CTD $\pm S E)$} & \multicolumn{4}{|c|}{ MFF (CTD $\pm S E)$} \\
\hline & $1 \mathrm{M} \pm \mathrm{SE}$ & $2 \mathrm{M} \pm \mathrm{SE}$ & $3 \mathrm{M} \pm \mathrm{SE}$ & $4 \mathrm{M} \pm \mathrm{SE}$ & $1 \mathrm{M} \pm \mathrm{SE}$ & $2 \mathrm{M} \pm \mathrm{SE}$ & $3 \mathrm{M} \pm \mathrm{SE}$ & $4 \mathrm{M} \pm \mathrm{SE}$ \\
\hline December & $0.57 \pm 0.35$ & $0.58 \pm 0.17$ & $1.33 \pm 0.84$ & $0.83 \pm 0.36$ & $0.95 \pm 0.24$ & $1.00 \pm 0.17$ & $1.44 \pm 0.32$ & $1.42 \pm 0.35$ \\
\hline January & $0.29 \pm 0.04$ & $0.62 \pm 0.12$ & $0.55 \pm 0.11$ & $0.63 \pm 0.052$ & $0.20 \pm 0.05$ & $0.20 \pm 0.02$ & $0.40 \pm 0.11$ & $0.33 \pm 0.02$ \\
\hline February & $0.43 \pm 0.09$ & $0.49 \pm 0.17$ & $0.82 \pm 0.16$ & $0.71 \pm 0.16$ & $0.10 \pm 0.03$ & $0.17 \pm 0.03$ & $0.25 \pm 0.05$ & $0.23 \pm 0.05$ \\
\hline March & $0.93 \pm 0.05$ & $1.10 \pm 0.14$ & $1.73 \pm 0.22$ & $1.54 \pm 0.14$ & $0.81 \pm 0.27$ & $1.16 \pm 0.37$ & $1.27 \pm 0.46$ & $1.26 \pm 0.41$ \\
\hline April & $1.51 \pm 0.19$ & $2.52 \pm 0.37$ & $3.87 \pm 0.52$ & $3.30 \pm 0.38$ & $1.35 \pm 0.06$ & $1.57 \pm 0.24$ & $2.10 \pm 0.25$ & $2.51 \pm 0.23$ \\
\hline May & $2.08 \pm 0.13$ & $2.67 \pm 0.21$ & $3.81 \pm 0.36$ & $3.79 \pm 0.39$ & $1.71 \pm 0.24$ & $1.85 \pm 0.26$ & $2.16 \pm 0.3$ & $2.50 \pm 0.34$ \\
\hline June & $2.63 \pm 0.35$ & $4.00 \pm 0.58$ & $4.60 \pm 0.23$ & $5.02 \pm 0.44$ & $1.94 \pm 0.28$ & $2.31 \pm 0.16$ & $2.85 \pm 0.08$ & $2.99 \pm 0.26$ \\
\hline July & $2.52 \pm 0.34$ & $2.93 \pm 0,21$ & $4.45 \pm 0.09$ & $4.12 \pm 0.35$ & $1.37 \pm 0.15$ & $1.42 \pm 0.03$ & $2.46 \pm 0.22$ & $2.85 \pm 0,52$ \\
\hline August & $3.65 \pm 0.43$ & $4.81 \pm 0.38$ & $5.94 \pm 0.38$ & $6.11 \pm 0.23$ & $1.29 \pm 0.15$ & $1.58 \pm 0.21$ & $2.10 \pm 0.27$ & $2.48 \pm 0.42$ \\
\hline September & $6.30 \pm 0.57$ & $6.79 \pm 0.64$ & $10.93 \pm 0.86$ & $10.04 \pm 1.38$ & $2.69 \pm 0.16$ & $3.89 \pm 0.23$ & $5.13 \pm 0.33$ & $5.51 \pm 0.52$ \\
\hline October & $6.80 \pm 0.48$ & $8.51 \pm 0,54$ & $12.86 \pm 0.13$ & $12.93 \pm 0.51$ & $4.65 \pm 0.31$ & $5.73 \pm 0.55$ & $7.88 \pm 0.81$ & $8.48 \pm 0.59$ \\
\hline November & $6.10 \pm 0.82$ & $7.97 \pm 1$ & $11.99 \pm 1.49$ & $11.49 \pm 1.16$ & $5.16 \pm 0.73$ & $6.75 \pm 0.53$ & $9.14 \pm 0.78$ & $8.88 \pm 0.67$ \\
\hline \multirow[t]{2}{*}{ MeanıSE } & $\begin{array}{c}2.83 \pm 0.33 \\
a\end{array}$ & $\begin{array}{c}3.64 \pm 0.4 \\
A\end{array}$ & $\begin{array}{c}5.32 \pm 0.606 \\
b\end{array}$ & $\begin{array}{c}5.12 \pm 0.59 \\
b\end{array}$ & $\begin{array}{c}1.9 \pm 0.23 \\
a\end{array}$ & $\begin{array}{c}2.36 \pm 0.29 \\
a b\end{array}$ & $\begin{array}{c}3.15 \pm 0.4 \\
b c\end{array}$ & $\begin{array}{c}3.34 \pm 0.4 \\
c\end{array}$ \\
\hline & \multicolumn{4}{|c|}{ L. S. D. $0.05=1.356$} & \multicolumn{4}{|c|}{ L. S. D. $0.05=0.928$} \\
\hline
\end{tabular}


DARWISH, A. A. E.

Table (3): Effect of the time of the day on the capture males of fruit flies (B. zonata and C. capitata) at Nubaria district, Beheira Governorate, Egypt:

\begin{tabular}{|c|c|c|c|c|c|c|c|c|}
\hline \multirow{3}{*}{ Months } & \multicolumn{8}{|c|}{ Time of day } \\
\hline & \multicolumn{4}{|c|}{ PFF CTD $\pm S E$} & \multicolumn{4}{|c|}{ MFF CTD $\pm S E$} \\
\hline & $7.00-10.00$ & $10.00-13.00$ & $13.00-16.00$ & $16.00-19.00$ & $7.00-10.00$ & $10.00-13.00$ & $13.00-16.00$ & $16.00-19.00$ \\
\hline December & $0.15 \pm 0.1$ & $0.05 \pm 0.023$ & $0.03 \pm 0.019$ & $0.03 \pm 0.027$ & $0.22 \pm 0.05$ & $0.07 \pm 0.02$ & $0.08 \pm 0.019$ & $0.03 \pm 0.016$ \\
\hline January & $0.12 \pm 0.045$ & $0.03 \pm 0.02$ & $0.01 \pm 0.015$ & 0 & $0.08 \pm 0.01$ & 0 & $0.01 \pm 0.013$ & 0 \\
\hline February & $0.17 \pm 0.028$ & $0.04 \pm 0.018$ & $0.01 \pm 0.008$ & $0.01 \pm 0.008$ & $0.03 \pm 0.02$ & 0 & $0.03 \pm 0.013$ & 0 \\
\hline March & $0.38 \pm 0.05$ & $0.07 \pm 0.02$ & $0.05 \pm 0.012$ & $0.04 \pm 0.007$ & $0.23 \pm 0.09$ & $0.03 \pm 0.012$ & $0.10 \pm 0.025$ & $0.04 \pm 0.02$ \\
\hline April & $0.72 \pm 0.12$ & $0.08 \pm 0.023$ & $0.10 \pm 0.017$ & $0.08 \pm 0.023$ & $0.42 \pm 0.03$ & $0.09 \pm 0.013$ & $0.12 \pm 0.017$ & $0.05 \pm 0.013$ \\
\hline May & $0.73 \pm 0.084$ & $0.07 \pm 0.013$ & $0.16 \pm 0.023$ & $0.09 \pm 0.023$ & $0.47 \pm 0.07$ & $0.10 \pm 0.011$ & $0.09 \pm 0.016$ & $0.02 \pm 0,006$ \\
\hline June & $1.01 \pm 0.034$ & $0.12 \pm 0.037$ & $0.13 \pm 0.019$ & $0.10 \pm 0.035$ & $0.54 \pm 0.05$ & $0.12 \pm 0.006$ & $0.13 \pm 0.013$ & $0.06 \pm 0.017$ \\
\hline July & $0.92 \pm 0.08$ & $0.03 \pm 0.007$ & $0.08 \pm 0.022$ & $0.04 \pm 0.025$ & $0.43 \pm 0.05$ & $0.11 \pm 0$ & $0.11 \pm 0.025$ & $0.02 \pm 0.007$ \\
\hline August & $1.28 \pm 0.12$ & $0.14 \pm 0.025$ & $0.21 \pm 0.032$ & $0.15 \pm 0.035$ & $0.36 \pm 0.05$ & $0.13 \pm 0.014$ & $0.07 \pm 0.018$ & $0.07 \pm 0.018$ \\
\hline September & $2.05 \pm 0.27$ & $0.48 \pm 0.106$ & $0.33 \pm 0.04$ & $0.19 \pm 0.036$ & $0.97 \pm 0.1$ & $0.2 \pm 0.028$ & $0.13 \pm 0.008$ & $0.13 \pm 0.017$ \\
\hline October & $2.40 \pm 0.11$ & $0.47 \pm 0.032$ & $0.35 \pm 0.063$ & $0.32 \pm 0.026$ & $1.50 \pm 0.15$ & $0.29 \pm 0.047$ & $0.32 \pm 0.034$ & $0.17 \pm 0.03$ \\
\hline November & $2.15 \pm 0.25$ & $0.54 \pm 0.076$ & $0.35 \pm 0.066$ & $0.23 \pm 0.042$ & $1.49 \pm 0.21$ & $0.29 \pm 0.045$ & $0.38 \pm 0.028$ & $0.23 \pm 0.03$ \\
\hline \multirow{2}{*}{ Mean $\pm S E$} & $\begin{array}{c}1.02 \pm 0.11 \\
a\end{array}$ & $\begin{array}{c}0.18 \pm 0.029 \\
b\end{array}$ & $\begin{array}{c}0.16 \pm 0.019 \\
b c\end{array}$ & $\begin{array}{c}0.11 \pm 0.015 \\
\text { bcd }\end{array}$ & $\begin{array}{c}0.59 \pm 0.07 \\
a\end{array}$ & $\begin{array}{c}0.12 \pm 0.014 \\
b c\end{array}$ & $\begin{array}{c}0.13 \pm 0.015 \\
b\end{array}$ & $\begin{array}{c}0.07 \pm 0.01 \\
\text { bcd }\end{array}$ \\
\hline & \multicolumn{4}{|c|}{ L. S. D. ${ }_{0.05}=0.161$} & \multicolumn{4}{|c|}{ L. S. D. $0.05=0.104$} \\
\hline
\end{tabular}

